\title{
Investigation on Sound Absorption of Rice - Straw Wood Particle Reinforced Composite
}

\author{
Mr.Khushal Raut ${ }^{1}$, Mr.Siddhesh Patil ${ }^{2}$, Mr. Kaivalya Raut ${ }^{3}$, Mr. Atharv Chaudhari ${ }^{4}$, \\ Dr.Buddharatna J. Godboley ${ }^{5}$ \\ ${ }^{1234}$ UG Students, Department of Civil Engineering, St John College of Engineering \& Management, Palghar \\ ${ }^{5}$ Associate Professor, Department of Civil Engineering, St John College of Engineering \& Management, Palghar
}

Received on: 10 May, 2021

Revised on: 07 June, 2021

Published on: 09 June, 2021

\begin{abstract}
In this study, rice straw wood particle composite boards for manufacture as insulation boards using the method used in the wood-based panel industry. the raw material, rice straw, was chosen because of its availability. The manufacturing parameters were a specific gravity of 0.4, 0.6, and 0.8, end rice content (10/90, 20/80, and 30/70) weight of rice straw/wood particle) of 10, 20, and $30 \mathrm{wt} . \%$. Commercial urea formaldehyde adhesive was used as the composite binder, to achieve 140-290 psi of bending modulus of rupture (MOR) with 0.4 specific gravity, 700 - 900 psi of bending amore with 0.6 specific gravity, and 1400 - 2900 psi of pending merge with 0.8 specific gravity. All of the composite boards for superior to insulation board in strength. Width and length of rice straw particle did not affect the bending more. The composite boards made from random cutting of rice straw and wood particles for the best and recommended for manufacturing processes. Sound absorption coefficients of the 0.4 and 0.6 specific gravity board were higher than other wood - based materials. The recommended properties of rice - straw wood particle composite boards are described, to absorb noises, preserve the temperature of indoor living spaces, and to be able to partially or completely substitute for wood particle and insulation board in wooden constructions.
\end{abstract}

Key Words: Rice Straw - wood particle composite board; insulation board; sound absorption coefficient

\section{1-INTRODUCTION}

$\mathbf{N}$ ise control and its principles play an important role in creating an acoustically pleasing environment. This can be achieved when the intensity of sound is brought down to a level that is not harmful to human ears. The demand for a better environment and more diversified lifestyle are increased. Achieving a pleasing environment can be obtained using various techniques that employ different materials. One such technique is by absorbing the sound and converting it to thermal energy. Sound absorbent materials are used within rooms or enclosed working areas to reduce reflection and thereby reduced the noise levels in the room. Therefore, the thin lightweight and low - cost materials that can absorb sound waves in wider frequency regions are strongly desired.

\section{II- OBJECTIVES}

- To identify the ability of rice straw as an absorbent material by finding the sound absorption coefficient.

- $\quad$ To meet the standards required for a high-class residential environment

- To meet demand caused by the decrease in supplies of solid wood and wood-based materials.

- Contribute to the recycling of agricultural wastes.

\section{III- METHODOLOGY}

\subsection{Selection of Materials}

- Wood Particle

- Rice straw

- Rice husk

- Resins

3.2 Collection of Materials 


\section{International Journal of Innovations in Engineering and Science, www.ijies.net}

- Commercial wood particles from furniture factory were used.

- The agricultural lignocellulosic fibers used in this study were rice straws \& rice husk collected from rice farm.

- Commercial UF resin adhesive (65 wt.\% of solid content) was used as the composite binder added with 10 wt.\% $\mathrm{NH} 4 \mathrm{Cl}$ solution as a hardener.

\subsection{Test On Materials}

- Moisture content and specific gravity to be examined using the ASTM D 1037-99 (American Society for Testing and Materials, 1999) method. Specific gravity was controlled by quality control testing; each value represents the average of five samples.

- 3-point bending strength was determined using a Universal Testing Machine.

\subsection{Design \& Casting}

All the specimens were mixed using hand mixing under desirable conditions and they are allowed for casting in the pre-fabricated moulds.

\subsection{Testing of Specimen:}

Parameters required for project are:
A) Compressive strength
B) Tensile strength

\section{IV- RESULTS \& DISCUSSIONS}

\subsection{Physical properties}

The moisture contents of the composite boards ranged from 7.28 to 9.53 wt.\%. The specific gravities were $0.17,0.35,0.57$, of the board prepared with the target SG of 0.2,0.4, and 0.6.

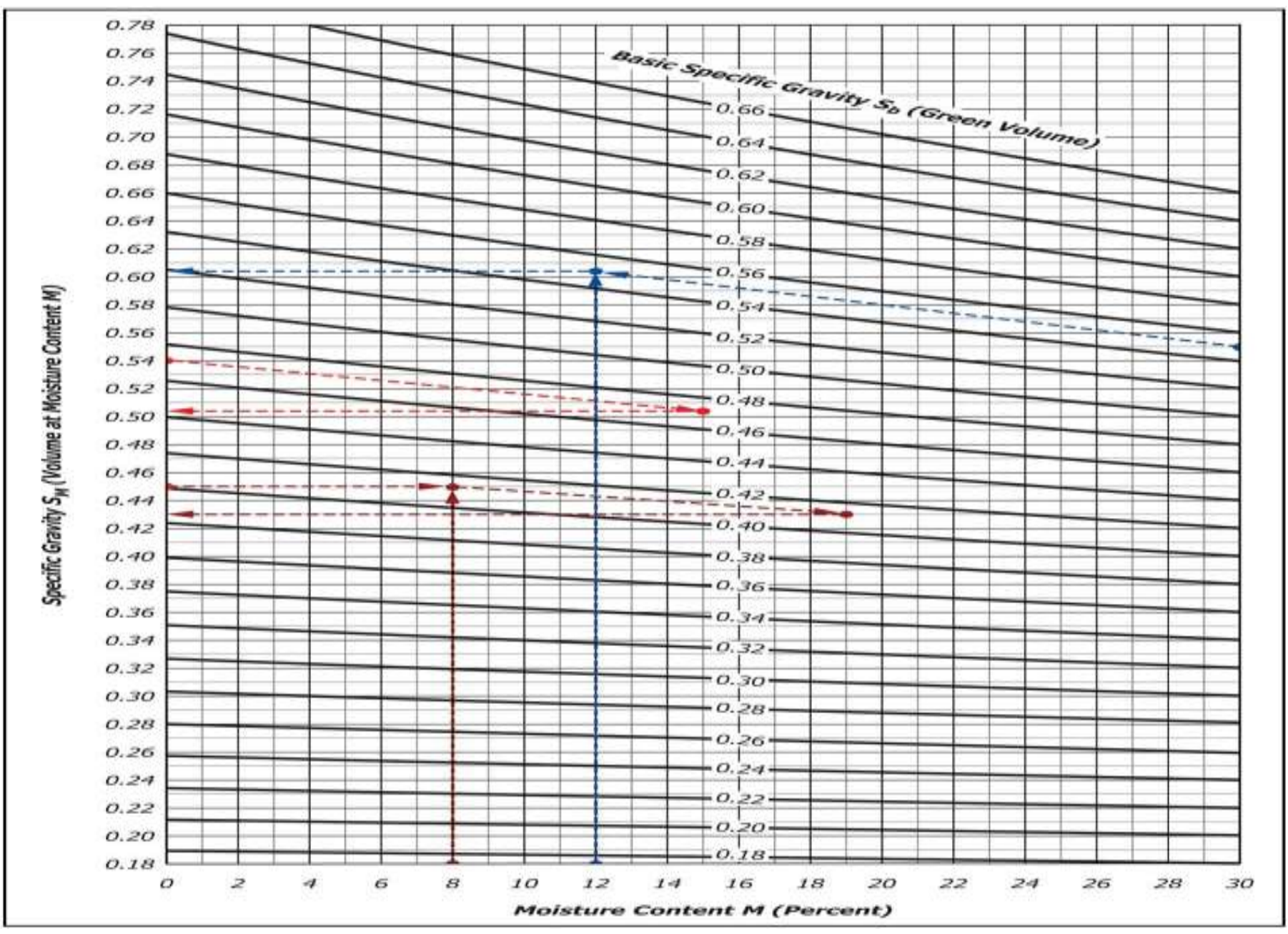




\section{International Journal of Innovations in Engineering and Science, www.ijies.net}

\subsection{Mechanical Properties}

It was found that rice straw content did not affect the bending MOR of the composite at low specific gravity (0.4 and 0.6). As the specific gravity of the composite was increased, the bending MOR also increased. Composite boards with low specific gravity had a lower bending MOR than composite boards with an SG of 0.8 .

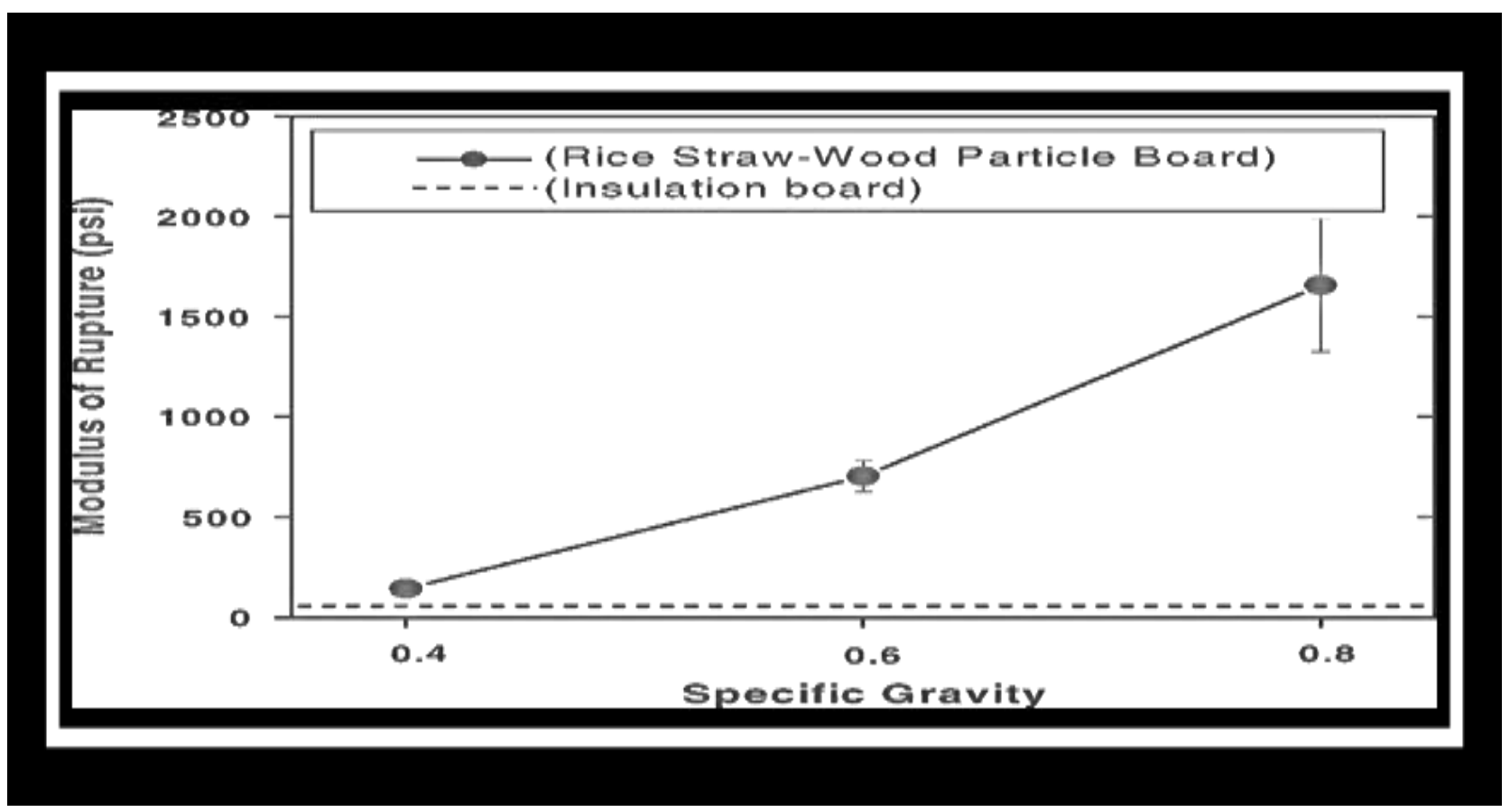

\subsection{Acoustical Property}

Composite boards with SG of 0.4 and 0.6 have higher sound absorption coefficients than particleboard, fiberboard, and plywood in the $500-8000 \mathrm{~Hz}$ frequency range, which is caused by the low specific gravity of composite boards, which are more porous than particleboard, fiberboard, and plywood. Composite boards with an SG of 0.8 show lower sound absorption coefficients than particleboard in the $1000-8000 \mathrm{~Hz}$ frequency range.

The sound absorption coefficients of composite boards with SG of 0.4 and 0.6 increased as the frequency increased. However, they decreased at the frequency of $1000 \mathrm{~Hz}$ and increased again. This decrease and increase was due to the specific characteristic of rice straw reflecting sound at $1000 \mathrm{~Hz}$ but absorbing sound in the middle and high frequency ranges.

\section{V- CONCLUSION}

The composite boards with an specific gravity of 0.8 have slightly better bending MOR than wood particleboard (as control board) at a rice straw content of $10 \mathrm{wt} . \%$, and show no differences from the control board at a $20 \mathrm{wt} . \%$ rice straw level. Rice straw can partially substitute for wood particles as raw materials at up to $20 \mathrm{wt} \%$ without reducing the bending strength. Composite boards mixed with random cut rice straws were similar to the other boards in strength, and thus, there is no need to screen agricultural fibers for size in the wood-based panel industry, which would have cost benefits. All of the composite boards with low specific gravity had a higher bending MOR than insulation board. The sound absorption coefficients of rice straw-wood particle composite boards were higher in the middle and high frequency range than commercial wood-based materials, such as particleboard, fiberboard, and plywood. These composite boards prepared with rice straw without considering the size and wood particles, with the specific gravities of 0.4 and 0.6 , were found to be suitable as a sound absorbing insulation material in wooden constructions. Since, rice husk is available in large amount, the potential for commercialization, especially for low frequency sound absorbent material is possible. 


\section{International Journal of Innovations in Engineering and Science, www.ijies.net}

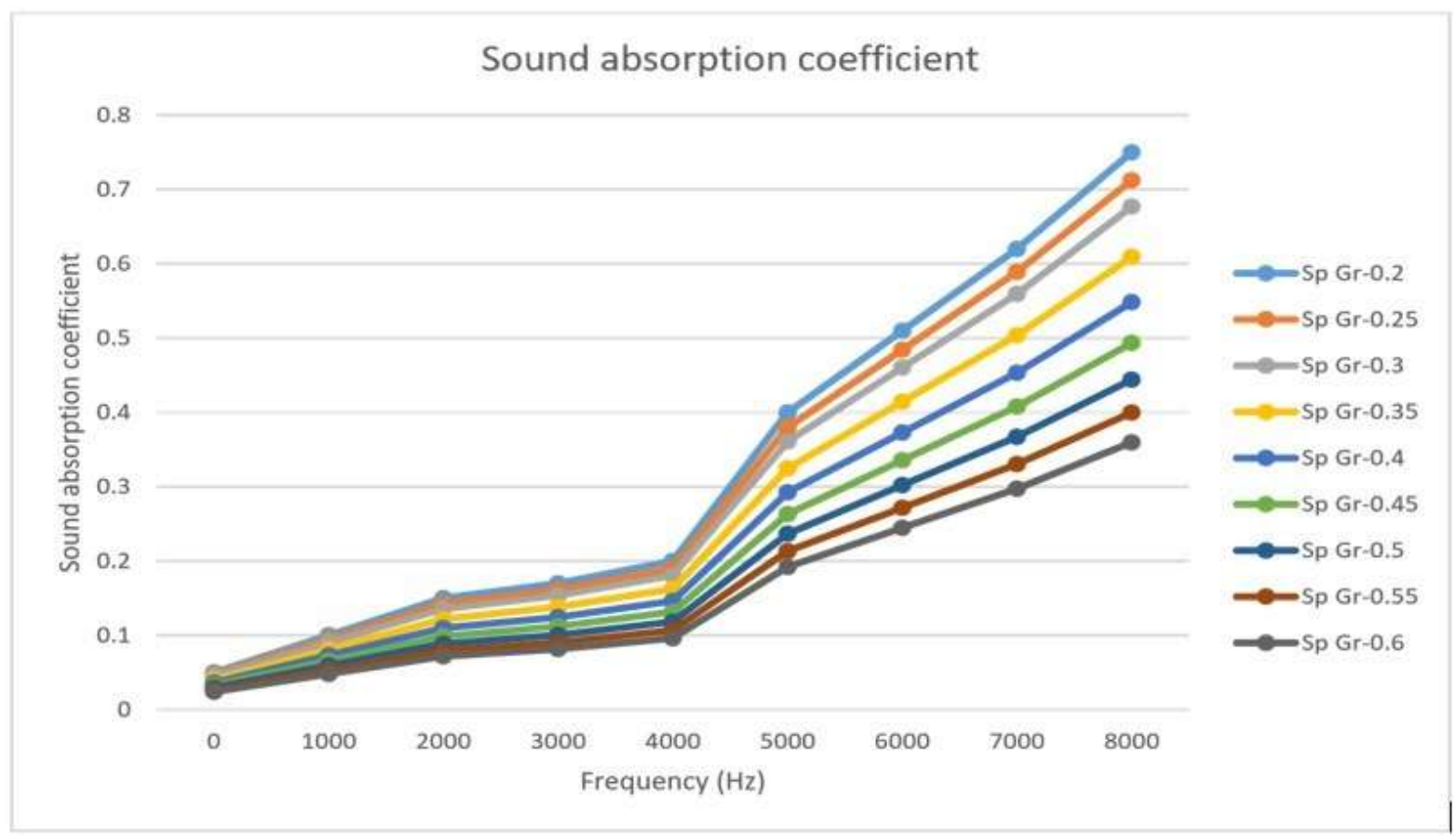

REFERENCES

[1] Ajiwe, V.I.E., Okeke, C.A., Ekwuozor, S.C., Uba, I.C., 1998. A pilot plant for production of ceiling boards from rice husks. Biores. Technol. 66, 41-43.

[2] American Society for Testing and Materials, 1999. Annual Book of ASTM Standards, Philadelphia, PA.

[3] Han, G., Zhang, C., Zhang, D., Umemura, K., Kawai, S., 1998. Upgrading of urea formaldehyde-bonded reed and wheat straw particleboards using silane coupling agents. J. Wood Sci. 44, 282-286.

[4] International Organization for Standardization, 1972. Fibre building boards-Determination of bending strength. ISO 7681972(E).

[5] Viswanathan, R., Gothandapani, L., 1999. Mechanical properties of coir pith particle board. Biores. Technol. 67, 93-95.

[6] Viswanathan, R., Gothandapani, L., Kailappan, R., 2000. Water absorption and swelling characteristics of coir pith particle board. Biores. Technol. 71, 93-94.

[7] Wagner, W.H., 1998. Modern Carpentry—building construction details in easy-to-understand form. The Goodheart-Willcox Company, Inc. pp. 325-333.

[8] Yalinkilic, M.K., Imamura, Y., Takahashi, M., Kalaycioglu, H., Nemli, G., Demirci, Z., Ozdemir, T., 1998. Biological, physical and mechanical properties of particleboard manufactured from waste tea leaves. Int. Biodeterior. Biodegrade. 41, 75-84. 